\title{
Factors associated with access to palliative home care in palliative patients at Lampang Hospital
}

\author{
Weerakorn Yongja^ ${ }^{\wedge}$ Phornwipa Panta, Napat Phetkub, Wararat Thatayu, Win Techakehakij \\ Department of Social Medicine, Lampang Hospital, Amphur Muang, Lampang, Thailand \\ Contributions: (I) Conception and design: All authors; (II) Administrative support: All authors; (III) Provision of study materials or patients: All \\ authors; (IV) Collection and assembly of data: All authors; (V) Data analysis and interpretation: All authors; (VI) Manuscript writing: All authors; (VII) \\ Final approval of manuscript: All authors. \\ Correspondence to: Win Techakehakij, MD, PhD. Department of Social Medicine, Lampang Hospital, Amphur Muang, Lampang 52000, Thailand. \\ Email: drwin123@gmail.com.
}

\begin{abstract}
Background Existing literature has shown the importance of palliative home care to improve quality of life among end-stage patients. However, access to palliative home care remains an issue. This study explores factors associated with successful delivery of palliative home care in palliative patients.

Methods: A retrospective study was conducted among patients who were referred to the palliative care team for consultation at Lampang Hospital from April 2020 to March 2021. Data from electronic medical records, including successful delivery of palliative home care, age, gender, public health insurance, admission department, primary disease (cancer, non-cancer), presenting symptoms (pain, dyspnea), palliative performance scale score and morphine use, were retrieved. Multiple logistic regression analysis was applied to explore the association, adjusting for covariates.

Results: A total of 370 patients were identified, with 88 (23.8\%) receiving palliative home care. Results showed that being female, having low palliative performance scale score, morphine use, and having Civil Servant Medical Benefit Scheme insurance are associated with a higher chance of having access to palliative home care, compared with their counterparts.

Conclusions: Results of this study pointed out health disparities among palliative patients who required palliative home care. This information can be in part used to redesign palliative home care system with the aim of improving access to care and patients' and caregivers' quality of life as a consequence.
\end{abstract}

Keywords: Palliative home care (PHC); health disparities; continuity of care; access to care

Submitted Oct 28, 2021. Accepted for publication Jan 27, 2022.

doi: 10.21037/apm-21-3161

View this article at: https://dx.doi.org/10.21037/apm-21-3161

\section{Introduction}

Palliative care (PC) is the end-of-life care provided for the purpose of supporting patients' medical, psychological and spiritual health (1). While the provision of PC is usually initiated at the hospitals, patients' and their caregivers' understandings about the care plan as well as relevant clinical knowledge and skills are deemed necessary to assure the quality of patient care at home.
This is as the palliative delivering system of each hospital could vary considerably. For example, a central hospital in the northern Thailand has a health professional team, including palliative physicians and nurses, which provide PC services for patients only at the hospital. After discharging the patients, health professionals, including physicians and nurses, at the primary care facilities respecting to the patients' home district will subsequently have the role to facilitate palliative services. However,

$\wedge$ ORCID: 0000-0003-4392-5524. 
success of the palliative service delivery at home depends on the completeness of the referral process from the hospital to the primary care. Information required during the referral includes the patient's medical information and specific cares required for each individual. Moreover, the availability of trained health professionals, essential medicines and instrument at the primary care setting, is also deemed crucial for continuous PC.

The continuity of PC system was set up as a medium to facilitate the delivery of high-quality PC seamlessly from hospital to patients' home. One important element to ascertain success of the continuity of care is the arrangement of medical professionals to visit patients' homes, called palliative home care (PHC) (2-4). PHC helps not only to reassure patients and caregivers about the provision of home care, but also explore gaps in service rendered for further assistance.

Existing literature indicated that PHC reduces the number of hospitalizations (5), unnecessary use of public health services $(6,7)$, and financial suffering of their family $(6,7)$. Moreover, access to PHC also prolongs patients' time spent with their families (4-8). Despite its benefits, studies show that $1.7-39.9 \%$ of end-of-life patients received PHC during the last time of life $(5,6,9)$. The main problems attributable to absence of PHC are the lack of knowledge and understanding in medical professionals, unclear referral criteria, socio-economic problems and being elderly (10).

While some research points out the problem regarding health disparity in access to PHC, there is still no evidence showing how well PHC was successfully delivered and its associated factors in the Southeast Asian populations. The objective of this study was to explore factors associated with successful delivery of PHC among palliative patients. We present the following article in accordance with the Strengthening the Reporting of Observational studies in Epidemiology (STROBE) reporting checklist (available at https://apm.amegroups.com/article/view/10.21037/apm21-3161/rc) (11).

\section{Methods}

\section{Design and sample}

A retrospective study was conducted using electronic medical records at Lampang Hospital. Information of patients, both out-patient and in-patient departments, who were referred to the PC team for consultation from April 2020 to March 2021 were collected. Patients who died during hospitalization were excluded. In case of that patients had palliative consultation more than once, only the data from the first-time consultation were considered.

\section{Covariates}

Data including age, gender, public health insurance, department (out-patient department/in-patient department), primary disease (cancer/non-cancer), presenting symptoms (pain, dyspnea) $(6,12,13)$, Palliative Performance Scale (PPS) score (14), morphine use (yes/no), were retrieved.

Pertaining to the mode of PHC delivery, PC teams might choose to perform it either by personal home visit or by phone $(15,16)$. Information about successful delivery of PHC was collected using secondary data, without differentiating between the two methods.

\section{Statistical analysis}

A Chi-square test was employed to examine the association between successful delivery of PHC and covariates. Multiple logistic regression analysis, with robust standard errors, was used to explore the association, adjusting for covariates. Stata version 13 (17) was applied in the analysis.

\section{Ethical approval}

The study was conducted in accordance with the Declaration of Helsinki (as revised in 2013). This research was approved by the Ethics Committee of Lampang Hospital (No. 77/64) and individual consent for this retrospective analysis was waived.

\section{Results}

A total of 370 palliative patients were identified, as demonstrated in Table 1. Of 370, 190 (51.4\%) were male. The patients' average age was 64 years. Seventyseven percent of the samples had cancer as their primary diagnosis, and $60.5 \%$ were from out-patient department. The majority of samples $(81.6 \%)$ were covered by the universal coverage insurance.

Concerning malignancy types, gastrointestinal cancer (24.0\%), hepatobiliary cancer $(22.2 \%)$, and lung cancer $(21.5 \%)$ were the three most common cancer types presenting in the patients. The types of cancer in patients were displayed in Table 2. When comparing the differences in receiving $\mathrm{PHC}$ among palliative patients, results 
Table 1 Demographic characteristics of the palliative patients $(\mathrm{N}=370)$

\begin{tabular}{|c|c|c|}
\hline Characteristics & $\mathrm{N}$ & $\%$ \\
\hline \multicolumn{3}{|l|}{ Sex } \\
\hline Male & 190 & 51.4 \\
\hline Female & 180 & 48.6 \\
\hline \multicolumn{3}{|l|}{ Age groups (years) } \\
\hline$\leq 40$ & 31 & 8.4 \\
\hline $41-60$ & 79 & 21.4 \\
\hline $61-80$ & 188 & 50.8 \\
\hline$>80$ & 72 & 19.5 \\
\hline \multicolumn{3}{|l|}{ Diseases } \\
\hline Cancer & 288 & 77.8 \\
\hline Non-cancer & 82 & 22.2 \\
\hline \multicolumn{3}{|l|}{ Department } \\
\hline Out-patient cases & 224 & 60.5 \\
\hline In-patient cases & 146 & 39.5 \\
\hline \multicolumn{3}{|l|}{ PPS score } \\
\hline $10-30$ & 112 & 30.3 \\
\hline $40-60$ & 197 & 53.2 \\
\hline $70-100$ & 61 & 16.5 \\
\hline \multicolumn{3}{|l|}{ Pain } \\
\hline No & 145 & 39.2 \\
\hline Yes & 225 & 60.8 \\
\hline \multicolumn{3}{|l|}{ Dyspnea } \\
\hline No & 165 & 44.6 \\
\hline Yes & 205 & 55.4 \\
\hline \multicolumn{3}{|l|}{ Morphine use } \\
\hline No & 64 & 17.3 \\
\hline Yes & 306 & 82.7 \\
\hline \multicolumn{3}{|l|}{ Health insurance } \\
\hline Universal Coverage & 302 & 81.6 \\
\hline Civil Servant Medical Benefit Scheme & 68 & 18.4 \\
\hline
\end{tabular}

PPS, Palliative Performance Scale.

indicated that being female $(\mathrm{P}=0.006)$, PPS score $(\mathrm{P}=0.013)$ and morphine used $(\mathrm{P}<0.001)$ were related to $\mathrm{PHC}$ access, as can be seen in Table 3 .

The association between access to PHC and covariates
Table 2 Types of cancer in palliative patient $(\mathrm{N}=288)$

\begin{tabular}{lcc}
\hline Cancer types & N & $\%$ \\
\hline Gastrointestinal & 69 & 24.0 \\
Hepatobiliary & 64 & 22.2 \\
Lung & 62 & 21.5 \\
Gynecology & 25 & 8.7 \\
Breast & 12 & 4.2 \\
Other & 56 & 19.4 \\
\hline
\end{tabular}

in palliative patients were displayed in Table 4. As demonstrated, males were associated with increased PHC, compared with females [odds ratio (OR) 2.262, 95\% confidence interval (CI): 1.337-3.824]. In comparison with patients with PPS score 70-100, those with PPS score 10-30 and 40-60 had $183.6 \%$ and $208.8 \%$ higher chances of having PHC access. Morphine used was also associated with increased access to PHC (OR 12.475, 95\% CI: 3.53444.034). Patients under the Civil Servant Medical Benefit Scheme insurance had 2.052 times higher odds of receiving PHC, compared with those under Universal Coverage insurance, with a 95\% CI: 1.082-3.891.

\section{Discussion}

Results of this study showed that $23.8 \%$ of the patients received $\mathrm{PHC}$, which was higher than the previously reported $1.7 \%$ and $7.5 \%$ in the Japanese and Italian study $(5,9)$. However, another existing study demonstrated a higher prevalence of $39.9 \%$ for successful PHC delivery (6). In spite of the presence of a relatively high proportion of successful PHC delivery, it appears that more than three quarters of patients still had no access to the service. Emphasis of this existing gap in service delivery remains crucial for further quality improvement of PHC system.

Further, the study discovered that being female, having low PPS score, morphine use, and having Civil Servant Medical Benefit Scheme insurance are associated with a higher chance of receiving PHC compared with their counterparts.

Regarding PPS score, it is noticed that patients with low PPS score inclined to receive PHC in relation to their peers. This could be explained by the fact that low PPS score indicates functional deterioration of the patients, in which clinical support from health professionals may be required. 
Table 3 Comparing the differences in receiving PHC among palliative patients

\begin{tabular}{|c|c|c|c|c|c|c|c|}
\hline \multirow{2}{*}{ Variables } & \multicolumn{2}{|c|}{ Total palliative patients } & \multicolumn{4}{|c|}{ Palliative home care } & \multirow{2}{*}{$P$ value } \\
\hline & $\mathrm{N}$ & $\%$ & $\mathrm{~N}$ & $\%$ & $\mathrm{~N}$ & $\%$ & \\
\hline Total & 370 & 100.0 & 88 & 23.8 & 282 & 76.2 & \\
\hline \multicolumn{8}{|l|}{ Sex } \\
\hline Female & 180 & 100.0 & 54 & 30.0 & 126 & 70.0 & \\
\hline \multicolumn{8}{|l|}{ Age groups (years) } \\
\hline$\leq 40$ & 31 & 100.0 & 4 & 12.9 & 27 & 87.1 & 0.276 \\
\hline $41-60$ & 79 & 100.0 & 16 & 20.3 & 63 & 79.7 & \\
\hline \multicolumn{8}{|l|}{ Diseases } \\
\hline Cancer & 288 & 100.0 & 68 & 23.6 & 220 & 76.4 & 0.884 \\
\hline Non-cancer & 82 & 100.0 & 20 & 24.4 & 62 & 75.6 & \\
\hline \multicolumn{8}{|l|}{ Department } \\
\hline Out-patient cases & 224 & 100.0 & 53 & 23.7 & 171 & 76.3 & 0.945 \\
\hline In-patient cases & 146 & 100.0 & 35 & 24.0 & 111 & 76.0 & \\
\hline \multicolumn{8}{|l|}{ PPS score } \\
\hline $10-30$ & 112 & 100.0 & 33 & 29.5 & 79 & 70.5 & 0.013 \\
\hline \multicolumn{8}{|l|}{ Dyspnea } \\
\hline No & 165 & 100.0 & 36 & 21.8 & 129 & 78.2 & 0.426 \\
\hline Yes & 205 & 100.0 & 52 & 25.4 & 153 & 74.6 & \\
\hline \multicolumn{8}{|l|}{ Morphine use } \\
\hline No & 64 & 100.0 & 3 & 4.7 & 61 & 95.3 & $<0.001$ \\
\hline Yes & 306 & 100.0 & 85 & 27.8 & 221 & 72.2 & \\
\hline \multicolumn{8}{|l|}{ Health insurance scheme } \\
\hline Universal Coverage & 302 & 100.0 & 66 & 21.9 & 236 & 78.2 & 0.066 \\
\hline Civil Servant Medical Benefit Scheme & 68 & 100.0 & 22 & 32.4 & 46 & 67.6 & \\
\hline
\end{tabular}

PHC, palliative home care; PPS, Palliative Performance Scale. 
Table 4 Factors associated palliative home care in palliative patients using multiple logistic regression analysis

\begin{tabular}{|c|c|c|c|}
\hline \multirow{2}{*}{ Variables } & \multirow{2}{*}{ Odds ratio } & \multicolumn{2}{|c|}{$95 \% \mathrm{Cl}$} \\
\hline & & Lower & Upper \\
\hline \multicolumn{4}{|l|}{ Sex } \\
\hline Male & Ref. & & \\
\hline Female & 2.262 & 1.337 & 3.824 \\
\hline \multicolumn{4}{|l|}{ Age (years) } \\
\hline$\leq 40$ & 2.590 & 0.791 & 8.473 \\
\hline $41-60$ & 3.083 & 1.041 & 9.129 \\
\hline $61-80$ & 3.370 & 1.036 & 10.964 \\
\hline$>80$ & Ref. & & \\
\hline \multicolumn{4}{|l|}{ Diseases } \\
\hline Non-cancer & Ref. & & \\
\hline Cancer & 0.615 & 0.279 & 1.356 \\
\hline \multicolumn{4}{|l|}{ Department } \\
\hline Out-patient cases & Ref. & & \\
\hline In-patient cases & 0.667 & 0.364 & 1.219 \\
\hline \multicolumn{4}{|l|}{ PPS score } \\
\hline $10-30$ & 2.836 & 1.089 & 7.383 \\
\hline $40-60$ & 3.088 & 1.087 & 8.770 \\
\hline $70-100$ & Ref. & & \\
\hline \multicolumn{4}{|l|}{ Pain } \\
\hline No & Ref. & & \\
\hline Yes & 0.769 & 0.354 & 1.667 \\
\hline \multicolumn{4}{|l|}{ Dyspnea } \\
\hline No & Ref. & & \\
\hline Yes & 0.978 & 0.537 & 1.782 \\
\hline \multicolumn{4}{|l|}{ Morphine use } \\
\hline No & Ref. & & \\
\hline Yes & 12.475 & 3.534 & 44.034 \\
\hline \multicolumn{4}{|l|}{ Health insurance scheme } \\
\hline Universal Coverage & Ref. & & \\
\hline $\begin{array}{l}\text { Civil Servant Medical Benefit } \\
\text { Scheme }\end{array}$ & 2.052 & 1.082 & 3.891 \\
\hline
\end{tabular}

$\mathrm{Cl}$, confidence interval; PPS, Palliative Performance Scale.

Results from the study also demonstrated that using morphine is highly associated with receiving PHC. This is as morphine is the medication used when patients were presented with disturbing symptoms, such as severe pain or dyspnea (8). Hence, PC teams may consider these patients the priority for $\mathrm{PHC}$ in order to evaluate patients' symptoms, drug compliance, and side effects, as adjustment of the drug dosage may be indicated in some patients.

This study discovers that female patient and those having Civil Servant Medical Benefit Scheme insurance inclined to have PHC access, in relation to their counterparts. While little is known about the influence of these factors on PHC access, future studies exploring in-depth about the relationship between these factors are recommended.

It is worth noting that the data used in this study were collected during the COVID-19 pandemic. The pandemic has impacted the health system, particularly the measures to reduce personal transport and contact, and increase the use of electronic device for providing medical consultation $(18,19)$. While this study revealed the prevalence of successful PHC delivery and its associated factors during COVID-19 pandemic, further research is recommended to explore the change in the PHC delivery after the COVID-19 era.

This research found no association between successful delivery of PHC and presence of pain or dyspnea. This implies the fact that, although the presence of disturbing symptoms is of concerns in PC, not all patients with such symptoms had access to PHC. Pertaining to this, there may be other domains relating to the symptom presentation, e.g., the level of severity, which indicate the need for $\mathrm{PHC}$, especially when the resource to supply PHC is scarce. Future research, examining the association between differential severity of disturbing symptoms and PHC access, is recommended to gain a better understanding of this issue.

As noted, this study explored only the first visit of PC consultation, whereas predicting factors of receiving $\mathrm{PHC}$ in the latter visits of patients may be different. This leaves a research opportunity for future study to explore.

Another issue worth noting is the inability to differentiate whether patients receive PHC by staff in person or by phone. During the era of COVID-19 pandemic, recommendations for the use of various types of telemedicine have been rapidly increasing. Regarding PHC, a study has revealed no difference in the outcome of patients' care between the use of in-person and byphone PHC (15). However, this issue may remain of concern that PHC by phone might reduce the quality of care and thus should only be used when appropriate. While factors prognosticating access to different modes of 
PHC delivery may differ, this study failed to elucidate due to data unavailability. This is acknowledged as the study's limitation.

\section{Conclusions}

While some evidence unveiled the limited access to PHC among palliative patients, little is known about its associated factors among the Southeast Asian populations. This study's highlight domains associated with successful delivery of PHC, which included being female, having low PPS score, morphine use, and having Civil Servant Medical Benefit Scheme insurance. Results of the study pointed out health disparities among palliative patients who required PHC. This information can be in part used to redesign PHC system with the aim of improving access to care and patients' and caregivers' quality of life as a consequence.

\section{Acknowledgments}

Funding: None.

\section{Footnote}

Reporting Checklist: The authors have completed the STROBE reporting checklist. Available at https://apm. amegroups.com/article/view/10.21037/apm-21-3161/rc

Data Sharing Statement: Available at https://apm.amegroups. com/article/view/10.21037/apm-21-3161/dss

Conflicts of Interest: All authors have completed the ICMJE uniform disclosure form (available at https://apm. amegroups.com/article/view/10.21037/apm-21-3161/coif). The authors have no conflicts of interest to declare.

Ethical Statement: The authors are accountable for all aspects of the work in ensuring that questions related to the accuracy or integrity of any part of the work are appropriately investigated and resolved. The study was conducted in accordance with the Declaration of Helsinki (as revised in 2013). This research was approved by the Ethics Committee of Lampang Hospital (No. 77/64) and individual consent for this retrospective analysis was waived.

Open Access Statement: This is an Open Access article distributed in accordance with the Creative Commons Attribution-NonCommercial-NoDerivs 4.0 International
License (CC BY-NC-ND 4.0), which permits the noncommercial replication and distribution of the article with the strict proviso that no changes or edits are made and the original work is properly cited (including links to both the formal publication through the relevant DOI and the license). See: https://creativecommons.org/licenses/by-nc-nd/4.0/.

\section{References}

1. Connor SR. editor. Global Atlas of Palliative Care 2nd Edition. London, UK 2020.

2. Auriemma CL, Nguyen CA, Bronheim R, et al. Stability of end-of-life preferences: a systematic review of the evidence. JAMA Intern Med 2014;174:1085-92.

3. Woodman C, Baillie J, Sivell S. The preferences and perspectives of family caregivers towards place of care for their relatives at the end-of-life. A systematic review and thematic synthesis of the qualitative evidence. BMJ Support Palliat Care 2016;6:418-29.

4. Enguidanos S, Rahman A, Fields T, et al. Expanding Access to Home-Based Palliative Care: A Randomized Controlled Trial Protocol. J Palliat Med 2019;22:58-65.

5. Costantini M, Higginson IJ, Boni L, et al. Effect of a palliative home care team on hospital admissions among patients with advanced cancer. Palliat Med 2003;17:315-21.

6. Riolfi M, Buja A, Zanardo C, et al. Effectiveness of palliative home-care services in reducing hospital admissions and determinants of hospitalization for terminally ill patients followed up by a palliative homecare team: a retrospective cohort study. Palliat Med 2014;28:403-11.

7. Lukas L, Foltz C, Paxton H. Hospital outcomes for a home-based palliative medicine consulting service. J Palliat Med 2013;16:179-84.

8. Mercadante S, Fulfaro F, Casuccio A. The impact of home palliative care on symptoms in advanced cancer patients. Support Care Cancer 2000;8:307-10.

9. Nakanishi M, Niimura J, Nishida A. Factors associated with end-of-life by home-visit nursing-care providers in Japan. Geriatr Gerontol Int 2017;17:991-8.

10. Ahmed N, Bestall JC, Ahmedzai SH, et al. Systematic review of the problems and issues of accessing specialist palliative care by patients, carers and health and social care professionals. Palliat Med 2004;18:525-42.

11. The Strengthening the Reporting of Observational Studies in Epidemiology (STROBE) Statement: guidelines for reporting observational studies [Internet]. Enhancing the QUAlity and Transparency Of health Research. [cited 20 
December,2021]. Available online: https://www.equatornetwork.org/reporting-guidelines/strobe/

12. Thayyil J, Cherumanalil JM. Assessment of status of patients receiving palliative home care and services provided in a rural area-kerala, India. Indian J Palliat Care 2012;18:213-8.

13. Kuroda K, Miura T, Kuroiwa S, et al. What are the factors that cause emergency home visit in home medical care in Japan? J Gen Fam Med 2020;22:81-6.

14. Ho F, Lau F, Downing MG, et al. A reliability and validity study of the Palliative Performance Scale. BMC Palliat Care 2008;7:10.

15. Schrijnemaekers V, Courtens A, Kuin A, et al. A comparison between telephone and bedside consultations given by palliative care consultation teams in the

Cite this article as: Yongja W, Panta P, Phetkub N, Thatayu W, Techakehakij W. Factors associated with access to palliative home care in palliative patients at Lampang Hospital. Ann Palliat Med 2022;11(6):1848-1854. doi: 10.21037/apm-21-3161
Netherlands: results from a two-year nationwide registration. J Pain Symptom Manage 2005;29:552-8.

16. Elfrink EJ, van der Rijt CC, van Boxtel RJ, et al. Problem solving by telephone in palliative care: use of a predetermined assessment tool within a program of home care technology. J Palliat Care 2002;18:105-10.

17. StataCorp. Stata Statistical Software: Release 13. 2013.

18. Ritchey KC, Foy A, McArdel E, et al. Reinventing Palliative Care Delivery in the Era of COVID-19: How Telemedicine Can Support End of Life Care. Am J Hosp Palliat Care 2020;37:992-7.

19. Olayemi LO, Abraham JA, Yemoh V, et al. Covid-19 and Palliative Care Delivery in Resource-Limited Settings: Healthcare Workers' Involvement. The Journal of Pacific Research 2021;21:458-64. 